\title{
Recruitment of lesser sandeel Ammodytes marinus in relation to density dependence and zooplankton composition
}

\author{
Mikael van Deurs ${ }^{1, *}$, Ralf van Hal $^{2}$, Maciej T. Tomczak ${ }^{1}$, Sigrún H. Jónasdóttir ${ }^{1}$, \\ Per Dolmer ${ }^{1}$
}

${ }^{1}$ National Institute of Aquatic Resources, Technical University of Denmark, Jægersborg Alle 1, Charlottenlund Castle, 2920 Charlottenlund, Denmark

${ }^{2}$ Institute for Marine Resources and Ecosystem Studies, Wageningen IMARES, Haringkade 1, 1976CP Ijmuiden, The Netherlands

\begin{abstract}
Recent recruitment failure of lesser sandeel Ammodytes marinus, a key prey fish in the North Sea, followed by several years of low spawning stock biomass, prompted us to investigate factors influencing the recruitment of this species. We tested 2 hypotheses that relate to ecological mechanisms of recruitment regulation in lesser sandeel: (1) a positive spawning stock-recruitment relationship is decoupled in years associated with high abundances of age-1 sandeels and (2) the survival success of early larvae depends specifically on the abundance of Calanus finmarchicus and not $C$. helgolandicus. The findings of the present study supported both hypotheses and resulted in a multiple linear recruitment model with pronounced predictive capabilities. The model includes interactions between age-1 abundance and spawning stock biomass, plus the effect of $C$. finmarchicus abundance, and it explained around $65 \%$ of the inter-annual variation in recruitment in contrast to only $12 \%$ by a traditional Ricker curve. We argue that early egg production in C. finmarchicus supports the survival of larvae, and that climate-generated shifts in the Calanus species composition lead to a mismatch in timing between food availability and the early life history of lesser sandeels.
\end{abstract}

KEY WORDS: Ammodytes marinus · Recruitment · Calanus finmarchicus · Match/mismatch hypothesis $\cdot$ Density dependency $\cdot$ Climate change

\section{INTRODUCTION}

In many ecosystems sandeel is a key prey fish linking trophic levels (Furness 1990, 2002, Hain et al. 1995, Frederiksen et al. 2005). The lesser sandeel Ammodytes marinus constitutes the vast majority of sandeels in the North Sea and one of the largest fish biomasses (Temming et al. 2004, ICES 2005), and has supported a large industrial fishery since the 1950s. The Danish fleet alone harvested between 500000 and $900000 t$ of sandeels every year during the peak of the fishery in the 1990s. Variability in the abundance of lesser sandeels is thus likely to have broad effects on the entire ecosystem and the fisheries. The number of young-of-the-year sandeels settling into adult aggregations was historically low in 2002, and, subsequently, the spawning stock biomass came to a critically low level. This drastic reduction in population size has made development of new forecast methods and identification of factors affecting sandeel population dynamics high priorities (ICES 2007).

Adult lesser sandeels (age-1 and older) are found in large parts of the North Sea, with a distribution closely related to well-oxygenated bottom substrates consisting of gravel or coarse sand, and water depths between 20 and $100 \mathrm{~m}$ (Reay 1970). They bury in the sand, when water temperature or prey abundance is low (Winslade 1974a,c), and at night when low light intensity limits 
prey visibility (Winslade 1974b). They reach sexual maturity at around age-2 and subsequently spawn in December/January (Macer 1966, Bergstad et al. 2001). The eggs stick to the substrate until they hatch during February and March (Macer 1965, Wright \& Bailey 1996), whereupon larvae are found in most of the water column (Conway et al. 1997). After metamorphosis they settle in sandy seabeds into the aggregations of adults. Sandeel recruitment is traditionally defined as the amount of post-settlement individuals in June. Consensus has been reached that after settling individuals show high site fidelity (e.g. Gauld 1990, Pedersen et al. 1999).

Fish populations, particularly of species with a short lifespan such as the sandeel, are highly sensitive to variation in recruitment. In general, predation and starvation mortality during early life stages is massive, but decreases rapidly with increasing size. Consequently, recruitment success largely depends on the growth rate experienced by the larvae. Varying availability of suitable prey in time and space, during early life history will therefore contribute to variation in recruitment (Cushing 1990).

It is well documented that zooplankton availability during the larval stage is critical for the recruitment of lesser sandeel (Arnott \& Ruxton 2002, Frederiksen et al. 2006) and of various other North Sea fish species (Economou 1991, Munk 1997, Gaard \& Reinert 2002). In the analysis conducted by Arnott \& Ruxton (2002), abundances of Calanus spp. Stage V and VI copepods in February were significantly related to recruitment of lesser sandeel. Arnott \& Ruxton (2002) argued that lesser sandeel larvae in February and March are too small to prey on Stage V and VI copepods and instead prey upon copepod eggs. Calanus spp. copepods are dominant components of the zooplankton community in the North Sea, and consist mainly of C. finmarchicus and C. helgolandicus. Spring egg production of $C$. helgolandicus reaches its maximum in May, whereas egg production by C. finmarchicus peaks in March at around 37 eggs female ${ }^{-1} \mathrm{~d}^{-1}$ in the shelf waters (Jónasdóttir et al. 2005). In addition, a proportion of the high production of $C$. finmarchicus eggs in the slope water drifts into the North Sea (Richardson et al. 1999). The early C. finmarchicus egg production coincides with the hatching of sandeel eggs. Back calculation in larval otoliths has established the hatch date of sandeels in Shetland waters to be between mid-February and early April (Wright \& Bailey 1996), and early larval stages ( $<6 \mathrm{~mm}$ ) of sandeels have been observed in the continuous plankton recorder (CPR) in the North Sea between mid-February and the end of March (reported in Wright \& Bailey 1996). Therefore, a shift from a C. finmarchicus-dominated community to a C. helgolandicus-dominated community is likely to cause a mismatch between the timing of prey availability and critical larval stages.
Carrying capacity refers to the maximum population size that can be sustained by resources within a habitat. Density dependence refers to population-regulating mechanisms inflicted by the population itself, for example, cannibalism or competition for habitat and food resources (Murdoch 1994).

Lesser sandeel is a non-migratory residential species associated with a defined habitat surface area, in which the spatial distribution of adults and juveniles overlap. These species characteristics favour the occurrence of density dependence and decoupling of the spawning stock-recruitment relationship when population size approaches carrying capacity.

The traditional way to account for density dependence and carrying capacity is by forcing non-linearity into the spawning stock-recruitment relationship. The Ricker stock-recruitment function (Ricker 1954) is one of various non-linear descriptions of this. Arnott \& Ruxton (2002) applied the Ricker stock-recruitment function to model the recruitment of lesser sandeels. However, their results suggested that the main factor inducing density dependence was not the spawning stock size, but the quantitatively dominant premature age-1 population, which is not accounted for in a traditional Ricker function.

In the present study we have extended the analyses done by Arnott \& Ruxton (2002), in order to further improve our understanding of the mechanisms involved in the recruitment regulation of lesser sandeels. To do this we used an updated time series, species-specific availability of copepods in the genus Calanus and interactions (non-additive effects) between the size of the age- 1 population and the spawning stock biomass to model the recruitment of lesser sandeels in the North Sea. The winter NAO index (mean of the North Atlantic Oscillation index between December and March) has been included in the analysis to account for the climate/temperature effect reported by Arnott \& Ruxton (2002).

We consider the 2 following hypotheses:

Hypothesis 1: The spawning stock-recruitment relationship is decoupled in years associated with high age-1 sandeel abundances.

Hypothesis 2: The survival success during early larval stages depends on the abundance of Calanus finmarchicus and not of $C$. helgolandicus.

\section{MATERIALS AND METHODS}

Data series. Population data for the North Sea sandeel Ammodytes marinus in ICES Division IV from 1983 to 2006 were taken from ICES seasonal stock assessments (ICES 2007). These data included spawning stock biomass (SSB) per million tonnes, and the 
numbers of recruits $\left(N_{0}\right)$ and age-1 individuals $\left(N_{1}\right)$ in billions. SSB and $N_{1}$ represent age-2+ and age-1 abundance in January, and are based on catch data. $N_{0}$ represents the number of age-0 juveniles (the cohort produced by the SSB in January) in the second half of the year, and is a virual population analysis-type backward calculation based on age-1 sandeel catches in the subsequent year and survey data (tuning data).

North Sea zooplankton data were sampled by the CPR program in the section of the North Sea referred to as ICES Division IVb, and provided by SAHFOS (Johns 2008). Data consisted of species-specific mean abundance (numbers $\mathrm{m}^{-3}$ ) in February of Stage V and VI calanoid copepods. The time series (1983 to 2006) used were: Calanus finmarchicus (FIN $\left.\mathrm{Feb}_{\mathrm{F}}\right), C$. helgolandicus $\left(\mathrm{HEL}_{\mathrm{Feb}}\right)$ and the combination of both $\left(\mathrm{CAL}_{\mathrm{Feb}}\right)$.

The winter North Atlantic Oscillation index $\left(\mathrm{NAO}_{\mathrm{DJFM}}\right)$, calculated as mean monthly values from December through March from the website of Jim Hurrell (www.cgd.ucar.edu/cas/jhurrell, accessed 7 February 2008) was used as a proxy for variation in climate.

Data analysis and modelling. Different modelling frameworks were applied to test Hypotheses 1 and 2: (1) a traditional Ricker stock-recruitment function with inherent density dependence (Ricker 1954) and (2) statistical model frameworks in the form of general additive modelling (GAM) and linear regression modelling (LM). GAM was used to statistically test non-linear relationships. The lm-, gam- and nls-functions of the programming environment $\mathrm{R}$ ( $\mathrm{R}$ Development Core Team 2007; with the mgcv library; Wood 2006) were used to fit the respective models. LM and GAM were applied with a Gaussian distribution, and GAM was applied using penalized regression splines with smoothing parameters selected by generalized crossvalidation (GCV) with shrinkage (fixed to a maximum of 4 degrees of freedom).

The Ricker stock-recruitment function with the inclusion of an extra explanatory variable was formulated as $N_{0}=a \mathrm{SSB} \times \exp (-g \mathrm{SSB})+\exp (X) C_{1}$ where $a, g$ and $c$ represent fitted coefficients. The term $\exp (X) c$ is optional, and $X$ can be any given additional explanatory variable. The function was fitted using nls, which determines the non-linear, least-squares estimates of the parameters.

The initial models were fitted to data series of $N_{1}$ and SSB as explanatory variables and $N_{0}$ as an independent variable. Non-additive effects related to interactions between SSB and $N_{1}$ were accounted for in the models. Explanatory variables or interaction terms that did not contribute significantly to the model $(\mathrm{p}<0.05$, F-test) were excluded, and the model parameters were re-estimated. The environmental drivers $\left(\mathrm{NAO}_{\mathrm{DJFM}}\right.$,

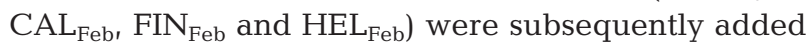
one by one to test whether they contributed significantly to the model.
Akaike's information criterion (AIC, Akaike 1974) takes into account the number of parameters in the model and was used to compare goodness of fit; $\mathrm{r}^{2}$ was used as a measure of the amount of inter-annual variation in $N_{0}$ explained by the model.

Bootstrap-based cross validation with 1000 iterations was used to confirm the reliability of the final best model. During each iteration, 12 of the $23 \mathrm{yr}$ in the time series were used to train the model, and predictions were made for the remaining $11 \mathrm{yr}$. Pearson's product moment correlation coefficient was used to express the prediction error for each iteration; therefore, the larger the correlation coefficient the smaller the prediction error.

For correlation analyses outside the models, correlation coefficients (r) and p-values (p) were calculated using the Pearson's product moment correlation analysis with Spearman's test.

\section{RESULTS}

\section{Initial fitting attempts and 1996}

Initial fits indicated that the model was extremely sensitive to 1 particular year in the data series, 1996. This year was associated with an unusual high $N_{0}$ of 1936 billion, which was 700 billion more than the second largest number in the entire time series. This unusually large $N_{0}$ coincided with an unusually low $\mathrm{NAO}_{\text {DJFM }}$ and an extremely cold winter. Including $\mathrm{NAO}_{\text {DJFM }}$ as an explanatory variable in the LM resulted in parameter estimates driven solely by 1996 (Cook's distance $=1.931)$. The subsequent analyses were conducted without 1996.

\section{Density dependence}

To test Hypothesis 1, that the spawning stockrecruitment relationship is decoupled in years associated with high abundances of age-1 sandeel Ammodytes marinus, recruitment modelling based on SSB, $N_{1}$ and their interactions was performed.

The smoothing parameters of a GAM fitted with additive effects were insignificant $(p \sim 0.15)$. It was not possible to include interactions because these consumed too many degrees of freedom.

The LM allowed for inclusion of interactions. The interaction between SSB and $N_{1}$ was significant ( $\mathrm{p}=$ 0.029 ), and $30 \%$ of the inter-annual variation in $N_{0}$ could be explained by this model (Table 1; Eq. 1a). It was therefore concluded that the LM framework was adequate for the purposes of the present study.

The traditional Ricker function explained $12 \%$ of the inter-annual variation in $N_{0}$ and was not significantly 
Table 1. Model results. $a, b, c, g$ and $k$ represent coefficients fitted to the model by least-squares linear regression; the given values are $\mathrm{p}$-values used to evaluate whether the estimated coefficient differed significantly from 0 . Akaike's information criterion (AIC) is given to compare model fits; $\mathrm{r}^{2}$ reflects the amount of variation explained by the fit: ${ }^{*} \mathrm{p}<0.05 ;{ }^{* *} \mathrm{p}<0.01 ;{ }^{* * *} \mathrm{p}<0.001$; $\mathrm{p}$-values for coefficients in the Ricker function are not directly comparable with p-values from linear regression modelling (LM) and general additive modelling (GAM) coefficients. For all other abbreviations see 'Materials and methods: Data series'

\begin{tabular}{|c|c|c|c|c|c|c|c|}
\hline \multirow[b]{2}{*}{ Models } & \multicolumn{5}{|c|}{ - Fitted coefficients ( $\mathrm{p}$-values) } & \multicolumn{2}{|c|}{ Comparison of models } \\
\hline & $k$ & $a$ & $b$ & $C$ & $g$ & $\mathrm{r}^{2}$ & AIC \\
\hline Eq. (1a) LM & & & & & & & \\
\hline$N_{0}=a \mathrm{SSB}+b N_{1}+g\left(\mathrm{SSB} \times N_{1}\right)+k$ & 0.5 & $0.018^{*}$ & 0.078 & & $0.029^{*}$ & 0.302 & 325.7 \\
\hline Eq. (1b) LM & & & & & & & \\
\hline$N_{0}=a \mathrm{SSB}+b N_{1}+c \mathrm{FIN}_{\mathrm{Feb}}+\left(g \mathrm{SSB} \times N_{1}\right)+k$ & 0.824 & $0.005^{* *}$ & $0.023^{*}$ & $<0.001^{* * *}$ & $0.008^{* *}$ & 0.649 & 311.9 \\
\hline $\begin{array}{l}\text { Eq. (2a) Ricker } \\
N_{0}=a \mathrm{SSB} \times \exp (-g \mathrm{SSB})+\exp \left(N_{1}\right) c\end{array}$ & & $0.001^{* *}$ & & 0.376 & $0.001^{* *}$ & 0.154 & 328.1 \\
\hline $\begin{array}{l}\text { Eq. (2b) Ricker } \\
N_{0}=a \mathrm{SSB} \times \exp (-g \mathrm{SSB})\end{array}$ & & $<0.001^{* * *}$ & & & $0.001^{* *}$ & 0.119 & 327.1 \\
\hline $\begin{array}{l}\text { Eq. (2c) Ricker } \\
N_{0}=a \mathrm{SSB} \times \exp (-g \mathrm{SSB})+\exp \left(\mathrm{FIN}_{\mathrm{Feb}}\right) c\end{array}$ & & $0.008^{* *}$ & & $<0.001^{* * *}$ & $0.006^{* *}$ & 0.501 & 328.1 \\
\hline
\end{tabular}

improved by adding $N_{1}$ as an additional explanatory variable (Table 1; Eq. 2a,b).

The significant interaction between SSB and $N_{1}$ was explored more closely. This was done by disaggregating the data into 3 subsets of equal sizes according to age-1 abundances of the respective years - Subset 1: $<145$ billion age-1 individuals, Subset 2: between 145 and 275 billion age-1 individuals and Subset 3: > 275 billion age-1 individuals. A significant positive linear relationship ( $\mathrm{r}=0.794, \mathrm{p}=0.019)$ existed between $N_{0}$ and SSB when age-1 abundance was low (Subset 1), while at high numbers (Subsets 2 \& 3), no relationship was found (Fig. 1).

In summary, we propose a linear recruitment model which accounts for interactions between spawning stock biomass and age-1 abundance. The results support Hypothesis 1 by showing that: (1) a linear recruitment model, which includes the $\mathrm{SSB}-N_{1}$ interaction, performs better than a linear model accounting for only additive effects and the traditional Ricker function and (2) that SSB is positively correlated to $N_{0}$, only when years of high $N_{1}$ were excluded.

\section{Species-specific Calanus abundance and the NAO}

During this stage of the analysis we tested Hypothesis 2 that the survival success of early larvae depends specif- ically on the abundance of $C$. finmarchicus and not $C$. helgolandicus.

The environmental drivers $\left(\mathrm{FIN}_{\mathrm{Feb}}, \mathrm{HEL}_{\mathrm{Feb}}, \mathrm{CAL}_{\mathrm{Feb}}\right.$ and $\left.\mathrm{NAO}_{\text {DJFM }}\right)$ were added one-by-one to the Ricker function and LM (Table 1; Eqs. 1a \& 2a). Only FIN $\mathrm{Feb}_{\mathrm{Feb}}$ contributed significantly to the models, and the estimated coefficients were positive (Table 2). The variation explained by the models increased in the LM from 30 to $65 \%$ and in the Ricker function from 12 to $50 \%$ (Table 1; Eqs. 1b \& 2c). There was no correlation or trend between FIN $_{\mathrm{Feb}}$ and the respective environmental drivers, HEL $\mathrm{Feb}, \mathrm{CAL}_{\mathrm{Feb}}$ and $\mathrm{NAO}_{\mathrm{DJFM}}$. HEL $\mathrm{Feb}_{\mathrm{Feb}}$ and $\mathrm{CAL}_{\mathrm{Feb}}$ were significantly, positively correlated

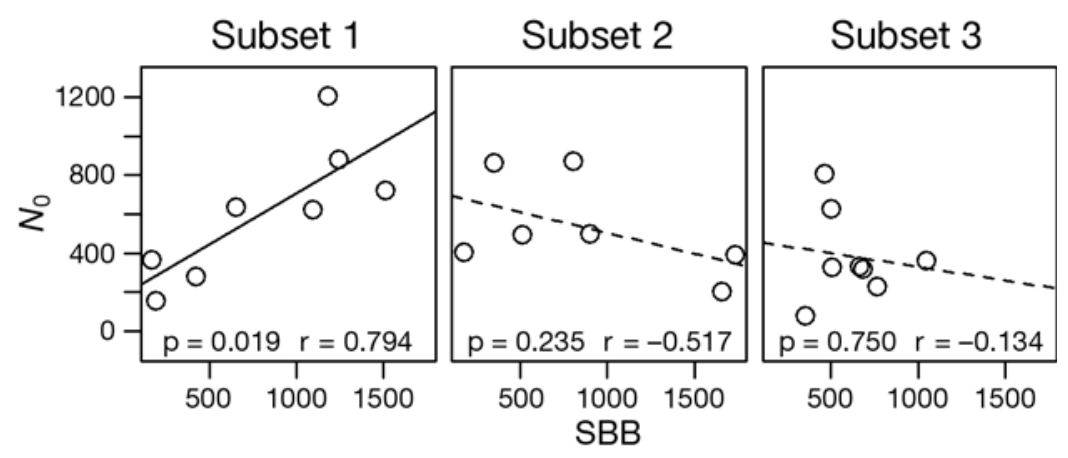

Fig. 1. Ammodytes marinus. Relationship between sandeel spawning stock biomass (SSB $\left[10^{3}\right.$ t of age- 2 and older]) and sandeel recruitment $\left(N_{0}\left[10^{9}\right.\right.$ age- 0 ind.]), under different scenarios of age- 1 sandeel abundances $\left(N_{1}\left[10^{9}\right.\right.$ age-1 ind.]). Data were disaggregated into 3 data subsets of equal sizes according to the age-1 abundance of the given year. Subset 1: <145 billion age-1 ind., Subset 2: between 145 and 275 billion age-1 ind. and Subset 3: $>275$ billion age- 1 ind. The stock recruitment relationship in each subset was analysed using Pearson's correlation analysis with Spearman's test. Correlation coefficients (r) and p-values (p) are provided. A solid regression line is provided when the relationship is significant 
Table 2. Including environmental drivers $\left(\mathrm{FIN}_{\mathrm{Feb}}, \mathrm{HEL}_{\mathrm{Feb}}\right.$ $\mathrm{CAL}_{\mathrm{Feb}}$ and $\mathrm{NAO}_{\mathrm{DJFM}}$ ) one-by-one in Eqs. (1a) \& (2a) (see Table 1). The table shows the estimated coefficients for each environmental explanatory variable; $\mathrm{p}$-values indicate whether the coefficients differed significantly from $0 .{ }^{* * *} \mathrm{p}<0.001$

\begin{tabular}{|lcrc|}
\hline Model & Environmental driver & Coefficients & $\mathrm{p}$ \\
\hline Eq. (1a) & FIN $_{\mathrm{Feb}}$ & 225.00 & $<0.001^{* * *}$ \\
Eq. (1a) & $\mathrm{HEL}_{\mathrm{Feb}}$ & -16.57 & 0.625 \\
Eq. (1a) & $\mathrm{CAL}_{\mathrm{Feb}}$ & 23.30 & 0.867 \\
Eq. (1a) & $\mathrm{NAO}_{\mathrm{DJFM}}$ & -5.13 & 0.447 \\
Eq. (2a) & $\mathrm{FIN}_{\mathrm{Feb}}$ & 54.46 & $<0.001^{* * *}$ \\
Eq. (2a) & $\mathrm{HEL}_{\mathrm{Feb}}$ & 0.01 & 0.748 \\
Eq. (2a) & $\mathrm{CAL}_{\mathrm{Feb}}$ & 0.01 & 0.699 \\
Eq. (2a) & $\mathrm{NAO}_{\mathrm{DJFM}}$ & -1.30 & 0.463 \\
\hline
\end{tabular}

$(\mathrm{r}=0.94, \mathrm{p}<0.001)$, and $\mathrm{CAL}_{\mathrm{Feb}}$ showed an insignificant negative trend with $\mathrm{NAO}_{\mathrm{DJFM}}(\mathrm{r}=0.36, \mathrm{p}=0.088)$.

The importance of a species-specific Calanus index was explored more closely. In Fig. 2, the 3 Calanus indices are plotted together, with the residuals from a modification of Eq. (1b) (see Table 1) in which FIN Feb $_{\text {a }}$ was replaced by $\mathrm{CAL}_{\mathrm{Feb}}$. The plot illustrates that when a high Calanus spp. abundance is driven by $\mathrm{HEL}_{\mathrm{Feb}}$, it usually coincides with overestimation of recruitment. On the contrary, when HEL $\mathrm{Feb}_{\text {and }}$ FIN $\mathrm{Feb}_{\mathrm{Fe}}$ contribute equally to overall abundance, the model tends to underestimate recruitment.

In summary, these results support Hypothesis 2 by showing: (1) that only FIN $_{\mathrm{Feb}}$ was significantly related to $N_{0}$ and (2) that large overall Calanus abundances driven by $C$. helgolandicus were associated with medium to low $N_{0}$.

\section{Model validation and selection}

The last step in the analysis involved model selection according to AIC and $\mathrm{r}^{2}$ and validation of the selected model using various methods. AIC was slightly lower for the final LM (Table 1; Eq. 1b) compared to the extended Ricker model (Table 1; Eq. 2c), and the final LM explained $65 \%$ of the inter-annual variation in $N_{0}$ compared to $50 \%$ in the extended Ricker function. Furthermore, it was regarded as a strength of the LM that, when fitted solely to population data (Table 1; Eq. 1a), the model could still explain as much as $30 \%$ of the variation compared to $12 \%$ in the Ricker model. Further model validation was therefore focused on the final LM (Table 1; Eq. 1b).

SSB showed a significant trend over time $(p=0.006)$, whereas there was no significant trend over time in the $N_{0}, N_{1}$, or FIN $N_{\text {Feb }}$ time series $(\mathrm{p}=0.237, \mathrm{p}=0.379, \mathrm{p}=$ 0.125 , respectively). 'Year' was included in the final LM as a dummy variable to test for effects of linear trends over time, and the coefficient estimate was insignificant $(p=0.529)$. However, values dropped in all time series in 2002 and remained at a relatively low level for the rest of the study period. The final LM was therefore refitted to a subset in which data from 2002 and onward had been removed, and the new estimated coefficients were significant for all explanatory variables (SSB: $\mathrm{p}=0.044 ; N_{1}: \mathrm{p}=0.043 ; \mathrm{FIN}_{\mathrm{Feb}}$ : $\mathrm{p}<0.001$; SSB $-N_{1}$ interaction: $\mathrm{p}=0.006$ ), which verified that the model was not driven by this drop.

Pairwise correlations of explanatory variables in the final LM showed no collinearity problems. Cook's distance analysis confirmed that the model was not influenced by single points driving the analysis. There was no autocorrelation in the model residuals, and they met the normality criteria (Kolmogorov-Smirnov test,

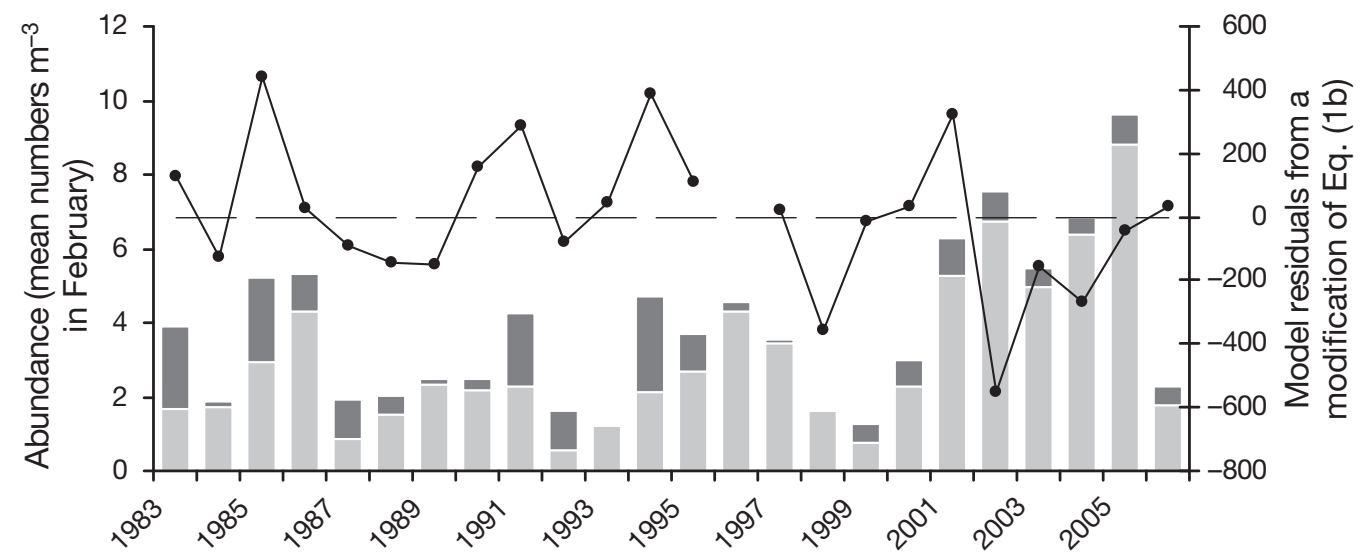

Fig. 2. Exploring the importance of a species-specific Calanus index. The histogram (left axis) is C. finmarchicus (dark grey columns) and $C$. helgolandicus (light grey columns). The line plot (right axis) shows model residuals from a modification of

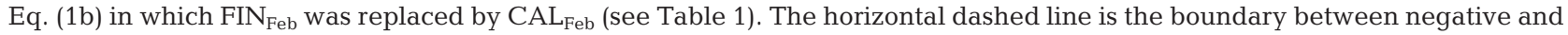
positive residuals (1996 is not plotted, see 'Materials and methods') 
$\mathrm{p}=0.126)$. Lastly, no trend was found in the model residuals versus the explanatory variables.

Fitted values from the final LM and observed $N_{0}$ values showed a high degree of covariation (for a dataset without 1996: $r=0.806, p<0.001$; Fig. 3A). Mean prediction error in the bootstrap-based cross validation was 0.582 , with $24.5 \%$ of 1000 iterations resulting in coefficients < 0.5 (Fig. 3B). The year 2002 was the only year (other than 1996) that completely departed from the pattern predicted by the model. If 2002 was left out during cross validation, the mean prediction error was considerably reduced, leading to an increase in the mean correlation coefficient from 0.582 to 0.780 . Furthermore, only $3.2 \%$ of 1000 iterations then resulted in coefficients $<0.5$ (Fig. 3C). The cross validation mean prediction error was slightly increased when the LM was trained mainly on years before 2000 (Fig. 3D)

The results of the model validation suggested that a linear model based on FIN $_{\mathrm{Feb}}$ and interactions between $N_{1}$ and SSB (Table 1; Eq. $1 \mathrm{~b}$ ) provides the most accu-
A
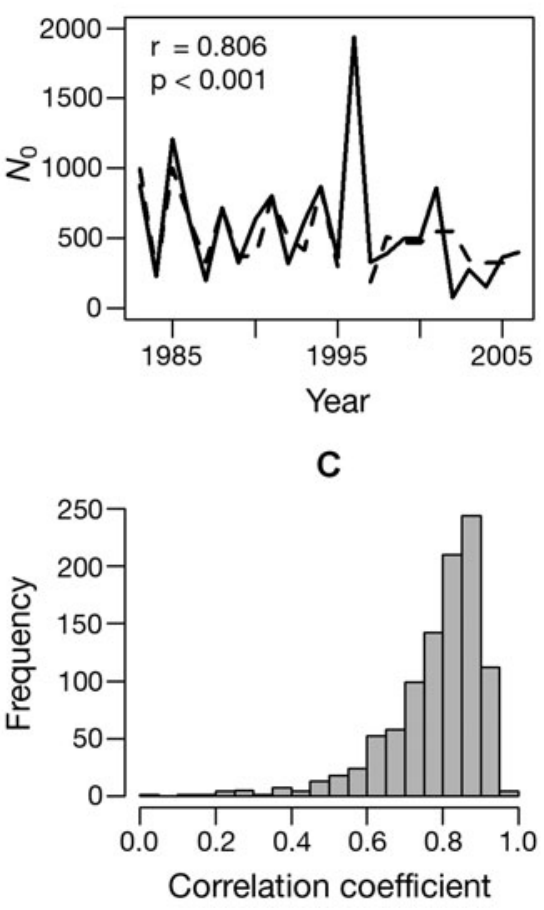

B

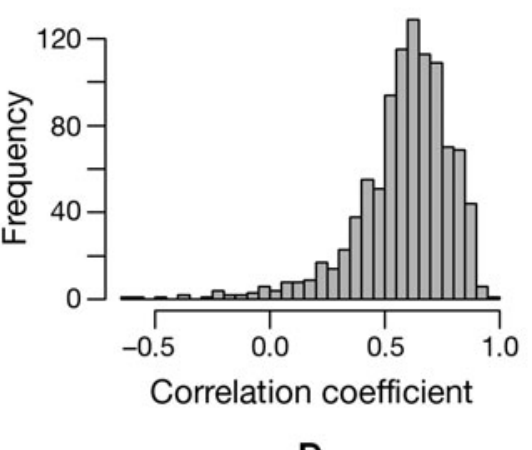

D

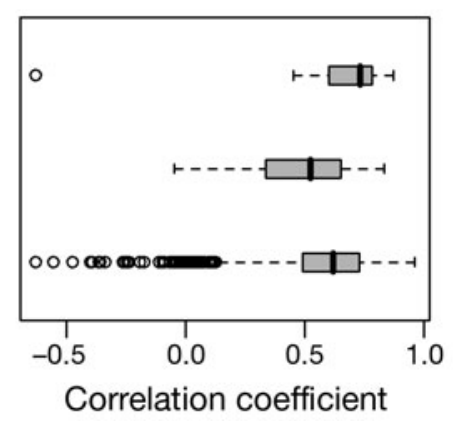

Fig. 3. Validating the linear regression modelling (Table 1; Eq. 1b). (A) Covariation plot of fitted values (broken line) versus observed values (solid lines). Note: the unusually high $N_{0}$ of 1996 was neither included in the model fitting nor in the covariation analysis. Pearson's correlation coefficient and p-value (Spearman's test) were calculated after removing 1996 data. (B) Distribution of prediction errors (Pearson's correlation coefficient) from bootstrap-based cross validation. (C) As for (B) but removing 2002 data. (D) Boxplot comparing the total distribution of prediction errors from the cross validation (lower box) to subsets of the prediction errors. Subset 1 is where only 1 yr after 1999 was included in the data subset used to train the model (middle box). Subset 2 is where only 1 yr before 1990 was included (upper box) rate and precise description of $N_{0}$ and that the predictive capability of such a model is rather high, considering the available time series.

\section{DISCUSSION}

\section{Density dependence}

The results of the present study support the findings by Arnott \& Ruxton (2002) that lesser sandeel Ammodytes marinus recruitment in the North Sea is under density-dependent regulation, mainly driven by the -1 population. However, the present results addially show how a positive relationship between was decoupled in years associated with a large population $\left(N_{1}\right)$. Consequently, inclusion of the interaction (non-additive effect) between SSB and $N_{1}$ was necessary in order to model recruitment. When SSB $-N_{1}$ interactions were included in the linear model, around $30 \%$ of the inter-annual variation in $N_{0}$ could be explained. In comparison, a traditional Ricker function explained no more than $12 \%$ of the variability in the recruitment. This result strongly suggests that the lesser sandeel population of the North Sea, between 1983 and 2006, made a shift between a state below carrying capacity, where the classical spawning stock-recruitment relationship prevailed, and a state above carrying capacity, where statedependence mediated by the age-1 population prevailed. In turn, this also explains why a simple additive (without interactions) spawning stockrecruitment relationship and a traditional Ricker function perform poorly (Arnott \& Ruxton 2002, ICES 2007, present paper).

A traditional Ricker function (Ricker 1954) has inherent density-dependent assumptions and models a positive spawning stock-recruitment relationship at a low spawning stock biomass and a negative relationship at a high spawning stock biomass. Furthermore, it does not take age-1 abundance into account. Since the age-1 population in most years by far outnumbers the spawning stock (ICES 2007), it is not surprising that density dependence is mediated mainly by age-1 abundance. 
The Ricker function, therefore, is an inadequate way to account for density dependence in a sandeel population. It should be noted that an attempt to include total population biomass or number was made. The attempt was unsuccessful, since these measures are related to SSB and causes collinearity among explanatory variables.

Cannibalism on eggs and larvae are common causes of density dependence. Lesser sandeels spawn in December/January, and the eggs stick to the substrate until they hatch during February and March (Wright \& Bailey 1996). Intra-specific predation on eggs and larvae by lesser sandeels may be insignificant, since the majority of lesser sandeels presumably reside passively in the sediment all winter (Reeves 1994), although a few fish may leave the sediment during winter, also outside the spawning period (Høines \& Bergstad 2001). Furthermore, its close relative, Ammodytes tobianus, seems incapable of bottom-feeding (M. van Deurs pers. obs.). Lesser sandeels generally forage between April and June, when zooplankton is most abundant (Winslade 1974c). By this time most larvae are $>20 \mathrm{~mm}$ and highly mobile (Wright \& Bailey 1996, Jensen et al. 2003). Therefore, they are highly unlikely to represent a significant food source for age-1 sandeels.

Another source of density dependence is competition for food resources. If the high concentrations of age-1 sandeels occurring in some years deplete food resources locally, newly metamorphosed sandeels would experience reduced growth. Biro et al. (2003) showed how density-dependent competition for food promotes risk-taking behaviour in age-0 rainbow trout Onchorhynchus mykiss as a strategy to counteract reduced energy uptake and thereby minimize the expected risk of overwinter starvation. In the case of age-0 sandeels, reduced growth could potentially force young sandeels to either prolong their feeding period and postpone the submerged low risk overwintering stage or to feed in more risky habitats further away from their sand refuge. Both scenarios would lead to increased predation mortality. The idea that young sandeels may be forced to postpone overwintering in years of poor growth conditions is consistent with observations of large quantities of age-0 individuals in the pelagic in September (Winslade 1974a, Reeves 1994).

\section{Species-specific Calanus abundance and the NAO}

The present study provides empirical documentation that sandeel recruitment in the North Sea is positively correlated to C. finmarchicus (Stages V and VI) abundance in February. In contrast, overall Calanus spp. or
C. helgolandicus abundance was not significantly correlated to recruitment. This is contrary to findings by Arnott \& Ruxton (2002), who found overall Calanus spp. abundance in February to be associated with North Sea sandeel recruitment. However, their time series extended from 1983 to 1999, and the species specificity observed in the present study was particularly pronounced after 1999, when a dramatic C. helgolandicus-driven increase in overall Calanus spp. abundance coincided with years of poor sandeel recruitment. The significance of the situation in recent years was also reflected in the model validation, which suggested that a full description of the covariate space was only possible if recent years were included when training the model.

In the North Sea, Calanus finmarchicus and C. helgolandicus are of equal size. Unfortunately, a comparison of female lipid content is not available. It is, however, known that both location and timing of egg production differs in these species (Jónasdóttir et al. 2005). A mismatch between the timing of prey availability and critical sandeel larval stages, therefore, provides the best explanation for the results presented here.

Dependence on a particular zooplankton species has been well documented for herring Clupea harengus, for example a decline in Pseudocalanus sp. abundance coincided with a 50 to $60 \%$ reduction in the mean weight at age for Baltic herring between 1980 and 1997 (Cardinale \& Arrhenius 2000, Möllmann et al. 2005). Furthermore, the horizontal distribution of North Sea herring during summer foraging changed according to a climate-driven shift in Calanus finmarchicus distribution (Corten 2000).

Horizontal distributions of Calanus finmarchicus and C. helgolandicus overlap in the North Sea, where their biogeographical boundaries meet (Planque \& Fromentin 1996). They display dissimilarities with respect to life cycles and temperature optimums, and climate has a significant influence on the horizontal distribution and regional species composition of these copepods (Fromentin \& Planque 1996, Heath et al. 1999, Beaugrand 2003). C. finmarchicus prefer deeper and colder water compared to C. helgolandicus and do not overwinter in the North Sea but off the shelf in deep Atlantic water. The overwintering stock of $C$. finmarchicus in the Faroe-Shetland Channel ascends to the surface, starting in February, with a peak in March and April, when north-westerly winds transport Stage V (CVs) and females into the North Sea (Heath 1999, Heath et al. 1999).

Since spatial and temporal variation in Calanus spp. composition and abundance is climate driven, it would be expected that the NAO at least indirectly affects sandeel recruitment. However, in the present 
study NAO $_{\text {DJFM }}$ was not found to covary with CPR measures of $C$. finmarchicus, but only with $C$. helgolandicus and overall Calanus spp. abundance. Heath et al. (1999) found that the inflow of $C$. finmarchicus from the Atlantic was influenced by the NAO, but the effect was only evident on decadal timescales and not from year to year, which could explain why the NAO, as a proxy for climate conditions, was not found to be associated with sandeel recruitment in the present study.

\section{Does the model overlook something?}

Model validation documented the reliability and predictive capabilities of the final linear model (Table 1; Eq. 1b). However, only when model fitting was carried out without 1996 did the resulting model emerge. The year 1996 was a climatic extreme associated with a dramatic shift in slope water circulation patterns in the NW Atlantic (Greene \& Pershing 2003), and coincided with an unusually large recruitment of lesser sandeels (Frederiksen et al. 2006, ICES 2007). Except for the concurrence of the highest recruitment and the lowest $\mathrm{NAO}_{\mathrm{DJFM}}$ in 1996, the NAO index applied in the present study did not contribute to the recruitment model. The link between the climatic phenomenon of 1996 and sandeel recruitment therefore remains unknown.

The year 2002 also deserves special attention. Predictive performance of the final LM was particularly high when 2002 was excluded. The spatial overlap between herring and sandeel in 2002 was, according to the catches from the Quarter 1 'International Bottom Trawl Survey' (data available from http://datras.ices.dk/ Home/Access.aspx, accessed May 2005), the largest of the entire time series analyzed in the present study (M. van Deurs unpubl. data). It has been suggested that herring influence sandeel recruitment in the Shetland population (Frederiksen et al. 2007), and sandeel larvae are often found in herring stomachs (Savage 1937, Pommeranz 1981, Last 1989). Hence, poor fit of the model in 2002 may be a consequence of unusually high predation pressure exerted by herring.

The analyses presented here target the entire stock located in ICES Division IVb east of $0^{\circ} \mathrm{E}$, also referred to as the North Sea sandeel. It has often been suggested that this stock should be regarded as a metapopulation consisting of a number of subpopulations separated by distance and the physical oceanography (e.g. Pedersen et al. 1999, Arnott \& Ruxton 2002). The sandeel populations along the east coast of Scotland and the Shetland Islands are already managed separately from the North Sea sandeel. However, we found that the scientific foundation for subdividing the North Sea sandeel into sub-components is still not solid enough to be applied. Furthermore, the long CPR time series and the population assessment data cannot support a spatially explicit analysis. The North Sea sandeel is found on most offshore sand banks in ICES Division IVb, but landings indicate that the Dogger area is quantitatively the most important area (ICES 2007). This area therefore largely drives the stock assessment from which the population data used in the present study were taken. The Dogger area has also experienced relatively good CPR coverage, and a CPR index for Calanus finmarchicus calculated for the Dogger area alone is highly correlated with that of the entire ICES Division IVb ( $\mathrm{c}=0.855, \mathrm{p}<0.001)$. It is therefore likely that the model proposed in the present study represents the sandeels populating the Dogger area rather than the more peripheral stock components.

\section{Perspectives}

The results of the present study provide an example of: (1) how models that account for density dependence should be specifically adapted to match the biology of the individual population and (2) how climate change may affect population dynamics indirectly by altering prey species composition.

During the last decade, regional Calanus species composition within the North Sea has changed significantly as a result of recent climate changes (Beaugrand 2003). Predictions indicate that these changes will persist or even increase (Pachauri \& Reisinger 2007). A large sandeel fishery has been exploiting the sandeel stock in the North Sea for decades, apparently without causing the stock to decline. The fishery mainly exploits the spawning stock biomass, which may not affect recruitment in stocks that are subjected to density-dependent regulation until the stock is below a critical limit. However, as shown in the present study, climatic forcing could potentially reduce the carrying capacity as it modifies the food resource and thereby forces the stock size below this critical limit. When the stock falls below the critical limit the spawning stock-recruitment relationship becomes important, and fishing mortality is now likely to indirectly affect recruitment by reducing the spawning stock. Depleted stocks are more vulnerable to changes in the environment (Brander 2005) and are therefore much more likely to crash. A decline in the North Sea sandeel stock will affect up to 10 species of predatory fishes (Engelhard et al. 2008), as well as a number of bird species and marine mammals (Furness 1990, Hain et al. 1995, Furness 2002, Frederiksen et al. 2005). 
Acknowledgements. The present study is part of the project In Ex Fish (www.liv.ac.uk/inexfish) financed by the Commission of the European Communities, specific RTD programme 'Specific Support to Policies', FP6 2004-SSP-4 'Integrating and Strengthening the European Research Area'. Thanks to SAHFOS for supplying data on zooplankton. We also thank K. Hüssy and J. Behrens for useful comments on the manuscript.

\section{LITERATURE CITED}

Akaike H (1974) A new look at the statistical model identification. IEEE Trans Automat Contr 19:716-723

> Arnott SA, Ruxton GD (2002) Sandeel recruitment in the North Sea: demographic, climatic and trophic effects. Mar Ecol Prog Ser 238:199-210

Beaugrand G (2003) Long-term changes in copepod abundance and diversity in the north-east Atlantic in relation to fluctuations in the hydroclimatic environment. Fish Oceanogr 12:270-283

> Bergstad OA, Høines AS, Kruger JEM (2001) Spawning time, age and size at maturity, and fecundity of sandeel, Ammodytes marinus, in the north-eastern North Sea and in unfished coastal waters off Norway. Aquat Living Resour 14:293-301

Biro PA, Post JR, Parkinson EA (2003) Density-dependent mortality is mediated by foraging activity for prey fish in whole-lake experiments. J Anim Ecol 72:546-555

Brander K (2005) Cod recruitment is strongly affected by climate when stock biomass is low. ICES J Mar Sci 62: 339-343

> Cardinale M, Arrhenius F (2000) Decreasing weight-at-age of Atlantic herring (Clupea harengus) from the Baltic Sea between 1986 and 1996: a statistical analysis. ICES J Mar Sci 57:882-893

Conway DVP, Coombs SH, Smith C (1997) Vertical distribution of fish eggs and larvae in the Irish Sea and southern North Sea. ICES J Mar Sci 54:136-147

$>$ Corten A (2000) A possible adaptation of herring feeding migrations to a change in timing of the Calanus finmarchicus season in the eastern North Sea. ICES J Mar Sci 57: 1261-1270

Cushing DH (1990) Plankton production and year-class strength in fish populations: an update of the match/mismatch hypothesis. Adv Mar Biol 26:249-292

Economou AN (1991) Food and feeding ecology of five gadoid larvae in the northern North Sea. J Cons Int Explor Mer 47:339-351

Engelhard GH, van der Kooij J, Bell ED, Pinnegar JK, Blanchard JL, Mackinson S, Righton DA (2008) Fishing mortality versus natural predation on diurnally migrating sandeels Ammodytes marinus. Mar Ecol Prog Ser 369: 213-227

Frederiksen M, Wright PJ, Heubeck M, Harris MP, Mavor RA, Wanless S (2005) Regional patterns of kittiwake Rissa tridactyla breeding success are related to variability in sandeel recruitment. Mar Ecol Prog Ser 300:201-211

Frederiksen M, Edwards M, Richardson AJ, Halliday NC, Wanless S (2006) From plankton to top predators: bottom up control of a marine food web across four trophic levels. J Anim Ecol 75:1259-1268

Frederiksen M, Furness W, Wanless S (2007) Regional variation in the role of bottom-up and top-down processes in controlling sandeel abundance in the North Sea. Mar Ecol Prog Ser 337:279-286

> Fromentin JM, Planque B (1996) Calanus and environment in the eastern North Atlantic. II. Influence of the North
Atlantic Oscillation on C. finmarchicus and C. helgolandicus. Mar Ecol Prog Ser 134:111-118

Furness RW (1990) A preliminary assessment of the quantities of Shetland sandeel taken by seabirds, seals, predatory fish and the industrial fishery in 1981-83. Ibis 132: 205-217

Furness RW (2002) Management implications of interactions between fisheries and sandeel-dependent seabirds and seals in the North Sea. ICES J Mar Sci 59:261-269

> Gaard E, Reinert J (2002) Pelagic cod and haddock juveniles on the Faeroe plateau: distribution, diets and feeding habitats 1994-1996. Sarsia 87:193-206

Gauld JA (1990) Movement of lesser sandeel (Ammodytes marinus Raitt) tagged in the northwestern North Sea. J Cons Int Explor Mer 46:229-231

Greene CH, Pershing AJ (2003) The flip-side of the North Atlantic Oscillation and modal shifts in slope-water circulation. Limnol Oceanogr 48:319-322

> Hain JHW, Ellis SL, Kenney RD, Clapham PJ, Gray BK, Weinrich MT, Babb IG (1995) Apparent bottom feeding by humpback whales on Stellwagen bank. Mar Mamm Sci 11:464-479

> Heath MR (1999) The ascent migration of Calanus finmarchicus from overwintering depth in the Faroe-Shetland Channel. Fish Oceanogr 8:84-99

> Heath MR, Backhaus JO, Richardson K, McKenzie B and others (1999) Climate fluctuations and the spring invasion of the North Sea by Calanus finmarchicus. Fish Oceanogr 8: 163-176

> Høines Ås, Bergstad OA (2001) Density of overwintering sandeel in the sand recorded by grab catches. Fish Res 49: 295-301

ICES (International Council for the Exploration of the Sea) (2005) Report of the study group on multispecies assessment in the North Sea. ICES CM 2005/D:06. International Council for the Exploration of the Sea, Copenhagen

ICES (2007) Report of the working group on the Assessment of the demersal stocks in the North Sea and Skagerrak. ICES CM 2007/ACFM:18. International Council for the Exploration of the Sea, Copenhagen

Jensen H, Wright P, Munk P (2003) Vertical distribution of pre-settled sandeel (Ammodytes marinus) in the North Sea in relation to size and environmental variables. ICES J Mar Sci 60:1342-1351

Johns D (2008) Monthly averaged data for Calanus finmarchicus and Calanus helgolandicus (ICES Division IVb) 19832006 as recorded by the Continuous Plankton Recorder. Sir Alister Hardy Foundation for Ocean Science, Plymouth

> Jónasdóttir SH, Trung NH, Hansen F, Gärtner S (2005) Egg production and hatching success in the calanoid copepods Calanus helgolandicus and Calanus finmarchicus in the North Sea from March to September 2001. J Plankton Res 27:1239-1259

- Last JM (1989) The food of herring, Clupea harengus, in the North-Sea, 1983-1986. J Fish Biol 34:489-501

Macer CT (1965) The distribution of larval sandeels (Ammodytidae) in the southern North Sea. J Mar Biol Assoc UK 45:187-207

Macer CT (1966) Sand eels (Ammodytidae) in the south-western North Sea: their biology and fishery. MAFF Fishery Invest Ser II 24(6):1-55

> Möllmann C, Kornilovs G, Fetter M, Köster FW (2005) Climate, zooplankton, and pelagic fish growth in the central Baltic Sea. ICES J Mar Sci 62:1270-1280

> Munk P (1997) Prey size spectra and prey availability of larval and small juvenile cod. J Fish Biol 51(Suppl A):340-351

$>$ Murdoch WW (1994) Population regulation in theory and practice. Ecology 75:271-287 
Pachauri RK, Reisinger A (2007) Climate Change 2007: Synthesis Report. Contribution of Working Groups I, II and III to the Fourth Assessment Report of the Intergovernmental Panel on Climate Change. IPCC, Geneva, Switzerland

Pedersen SA, Lewy P, Wright P (1999) Assessments of the lesser sandeel (Ammodytes marinus) in the North Sea based on revised stock divisions. Fish Res 41:221-241

Planque B, Fromentin JM (1996) Calanus and environment in the eastern North Atlantic. I. Spatial and temporal patterns of C. finmarchicus and C. helgolandicus. Mar Ecol Prog Ser 134:101-109

Pommeranz T (1981) Observations on the predation of herring (Clupea harengus L.) and sprat (Sprattus sprattus L.) on fish eggs and larvae in the southern North Sea. Rapp P-V Reun Cons Int Explor Mer 178:402-404

R Development Core Team (2007) R: a language and environment for statistical computing. R Development Core Team, Vienna. Available at: www.rcran.org (Accessed 14 June 2008)

Reay PJ (1970) Synopsis of the biological data on North Atlantic sand eels of the genus Ammodytes. Fisheries Synopsis No. 82. Food and Agriculture Organization of the United Nations, Rome

Reeves SA (1994) Seasonal and annual variation in catchability of sandeels at Shetland. ICES/Comm Meet D:19

Richardson K, Jónasdóttir SH, Hay SJ, Christoffersen A (1999) Calanus finmarchicus egg production and food availabil-

Editorial responsibility: William Peterson,

Newport, Oregon, USA ity in the Faroe-Shetland Channel and northern North Sea: October-March. Fish Oceanogr 8:153-162

Ricker WE (1954) Stock and recruitment. Can J Fish Aquat Sci 11:559-623

Savage RE (1937) The food of North Sea herring 1930-1934. Fishery Invest Ser II 24(6):1-55

Temming A, Gotz S, Mergardt N, Ehrich S (2004) Predation of whiting and haddock on sandeel: aggregative response, competition and diel periodicity. J Fish Biol 64: 1351-1372

- Winslade P (1974a) Behavioural studies on the lesser sandeel Ammodytes marinus (Raitt). I. The effect of food availability on activity and the role of olfaction in food detection. J Fish Biol 6:565-576

Winslade P (1974b) Behavioural studies on the lesser sandeel Ammodytes marinus (Raitt). II. The effect of light intensity on activity. J Fish Biol 6:577-586

> Winslade P (1974c) Behavioural studies on the lesser sandeel Ammodytes marinus (Raitt) III. The effect of temperature on activity and the environmental control of the annual cycle of activity. J Fish Biol 6:587-599

Wood SN (2006) Generalized additive models: an introduction with R. Chapman and Hall/CRC, New York

Wright PJ, Bailey MC (1996) Timing of hatching in Ammodytes marinus from Shetland waters and its significance to early growth and survivorship. Mar Biol 126:143-152

Submitted: September 25, 2008; Accepted: February 10, 2009 Proofs received from author(s): April 1, 2009 